\title{
PADRÕES DE EVAPOTRANSPIRAÇÃO EM ÁREA DE CERRADO PARA CENÁRIOS DE AQUECIMENTO COM SIMULAÇÕES DO MODELO SiB2
}

\author{
Gabriel B. Costa ${ }^{1}$, Humberto R. da Rocha ${ }^{1},{ }^{1}$ Monica R. Queiroz, Hélber C. de Freitas ${ }^{1}$ \\ ${ }^{1}$ Laboratório de Clima e Biosfera, IAG/USP \\ gabrielbc@iag.usp.br
}

\section{INTRODUÇÃO}

Atualmente, há uma grande preocupação científica sobre as mudanças climáticas, priorizadas pelo "World Climate Research" (WRCP) e pelo "Intergovernamental Panel on Climate Change" (IPCC, 2007). Para o entendimento destas mudanças, utilizam-se modelos físico-matemáticos para obtenção de prognósticos de futuros cenários climáticos. A modelagem atmosférica vem se mostrando fundamental nos estudos sobre mudanças climáticas devido à mudança do uso do solo e variabilidade climática. $\mathrm{O}$ balanço energético é uma excelente ferramenta para monitorar as condições ideais de manutenção de culturas agrícolas e ecossistemas nativos, uma vez que muitos estudos monitoram há anos os padrões sazonais da partição de energia nas condições climáticas atuais. Saber como esta partição será alterada devido a mudanças no clima pode favorecer medidas mitigadoras com o intuito de minimizar danos irreparáveis ao meio ambiente e á sociedade. Com base nisto, avaliou-se o impacto do aumento de até $5^{\circ} \mathrm{C}$ na temperatura do ar na evapotranspiração em uma área de Cerrado, através de simulações do modelo SIB2.

\section{MATERIAIS E MÉTODOS}

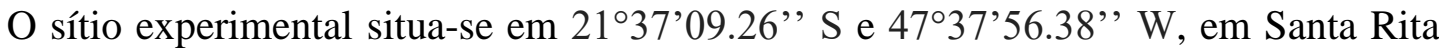
do Passa Quatro (SP). Mais informações sobre a estrutura do modelo SiB2 podem ser encontradas em Llopart (2009). Os fluxos de energia são funções explicitas de: condições de contorno atmosféricas; das variáveis prognosticas do $\mathrm{SiB} 2$; das três resistências aerodinâmicas $\left(r_{a}, r_{b}\right.$ e $\left.r_{d}\right)$ e das resistências de superfície $\left(r_{c}\right.$ e $r_{\text {solo. }}$. A evapotranspiração do dossel $\mathrm{E}_{\mathrm{c}}$ divide-se em duas componentes: $\mathrm{E}_{\mathrm{ci}}$, evaporação da água interceptada pelo dossel $\mathrm{E}_{\mathrm{ct}}$ transpiração da parte seca das folhas proveniente da extração de água do sistema radicular. Houve um acréscimo de $1^{\circ} \mathrm{C}$ temperatura do ar, a partir da série original até $5^{\circ} \mathrm{C}(1$ ano de dados, para 2006). Com os resultados, foi feito um ciclo médio diário para cada simulação.

\section{RESULTADOS E DISCUSSÃO}

O ciclo médio diário da evapotranspiração é representado na figura 1. Observa-se que há uma tendência de aumento na evapotranspiração à medida que se aumenta a temperatura do ar nas simulações. Este aumento se mostra maior a cada cenário somente a partir das 08:00h até ás 14:00h. Antes desse horário, o aumento de temperatura não ocasiona grande mudanças, e após este horário, parece haver um efeito de controle estomático da vegetação: Mesmo aumentando-se a temperatura do ar, não se têm aumentos consideráveis na evapotranspiração, provavelmente devido ao fechamento dos estômatos devido ao aquecimento, mecanismo que a vegetação utiliza para evitar perdas excessivas de água por transpiração devido as altas temperaturas. 


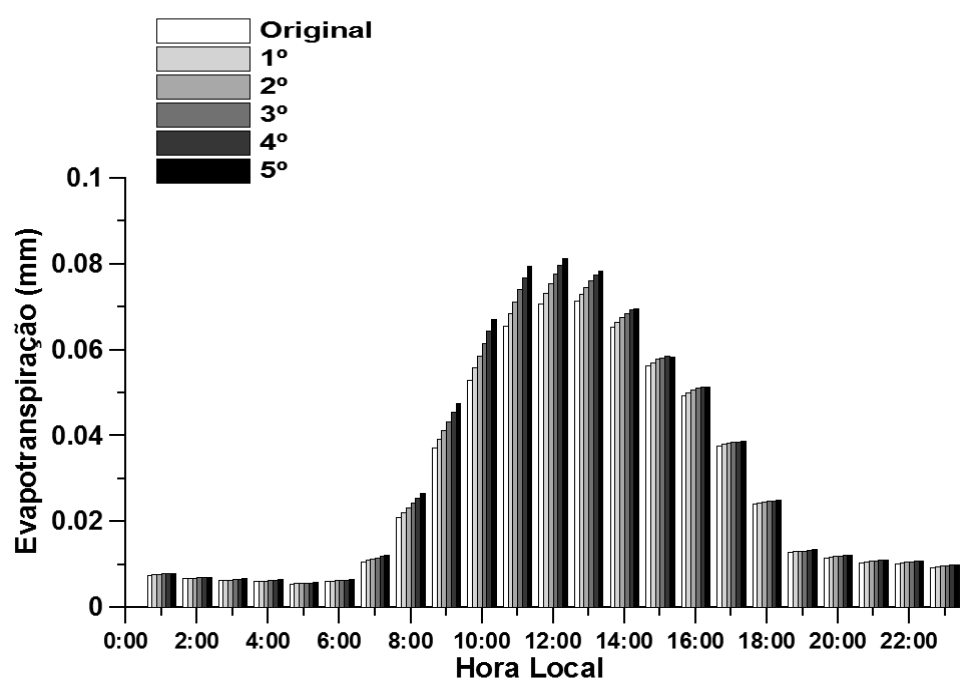

Figura 1. Ciclo diurno médio da evapotranspiração para os cenários de aumento de temperatura simulados.

Este aumento na evapotranspiração pode também ser observado no fluxo de calor latente (figura 2), indicando que o aumento da temperatura do ar afeta diretamente a partição de energia, fazendo com que se utilize mais energia do saldo de radiação para evaporar a água do sistema.

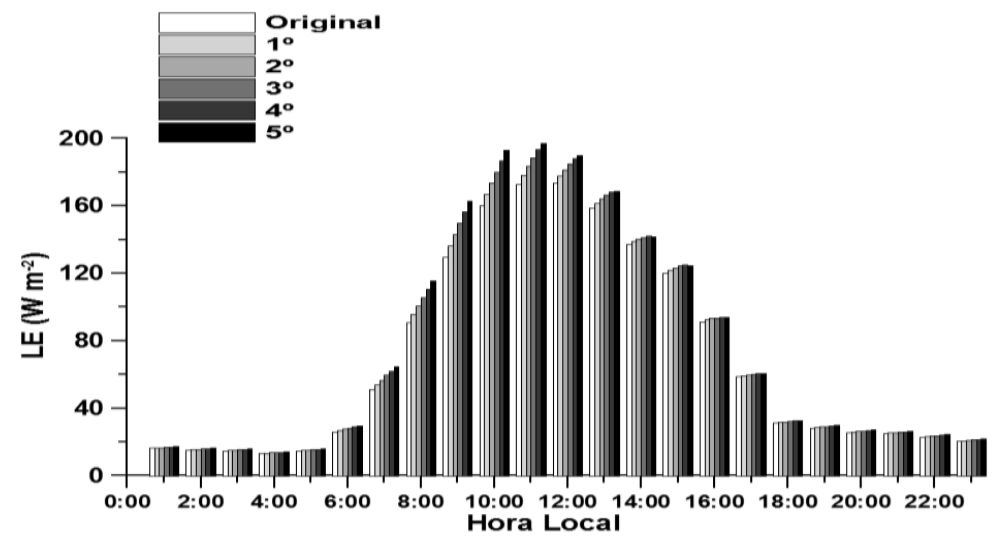

Figura 2. Ciclo diurno médio do fluxo de calor latente para os cenários de aumento de temperatura simulados.

\section{CONCLUSÕES}

Os resultados mostram que o aumento de temperatura do ar ocasionaria um aumento nos padrões de calor latente e evapotranspiração em determinados períodos do dia, provavelmente por ser o horário de maior atividade metabólica e trocas gasosas entre a biosfera e a atmosfera, não demonstrando maiores alterações no período da tarde principalmente ao provável controle estomático da vegetação devido às altas temperaturas.

\section{REFERÊNCIAS}


IPCC, Climate Change 2007 - The Physical Science Basis. Contribution of Working Group I to the Fourth Assessment Report of the IPCC. Cambridge Univ. Press, Cambridge, 2007.

LLOPART, M.P. Calibração do modelo sib2 em módulos seqüenciais para a floresta tropical amazônica. Dissertação (Mestrado em Meteorologia), USP, São Paulo, 2009. 